\title{
Nudging Small Business Owners to Adopt Workplace Retirement Plans
}

By

Peter W. Kirtland, University of South Florida

T

here are currently over 55 million working Americans that do not have access to a workplace retirement plan (CRI, 2018). Small business owners, employing 50 or fewer employees, are a significant catalyst to this problem. $67 \%$ of small business owners do not offer their employees a workplace retirement plan (GAO, 2017), and 33 million Americans work for a small business (GAO, 2017).

There is a significant difference in retirement preparedness between workers that have access to a workplace retirement plan and those who do not, as illustrated in Figure l (following page).

When workers are not offered a workplace retirement plan, $67 \%$ have less than $\$ 1,000$ saved for retirement. But when they do have access to a plan, that figure goes down to $9 \%$.

The research described in this paper was shown to increase workplace retirement plan adoption with small business owners through the application of a unique combination of two artefacts.
The purpose of this research is to discover why small business owners are so much more likely to not offer a workplace retirement plan compared to larger companies and what methods we can employ to increase that adoption rate.

Keywords: Adaptive Default Nudge, Coverage Crisis, Elicitation Script, Information Asymmetry, Nudging, Retirement Savings Crisis, Status Quo Bias 


\section{Methodology}

I use action design research as the method of research. This allows me to work through several cycles to diagnose the problem, design artefacts based on what I learned in the Diagnosis Cycle and implement the artefacts I designed in the Design Cycle during the Implementation Cycle. This method is also iterative by its nature, allowing for reflections and improvements throughout the research..

\section{Findings}

Through the Diagnosis Cycle I interviewed industry experts and small business owners, learning that there is an information void that is unique to small business owners. Financial advisors are the main source of information about workplace retirement plan options for most employers, but not for small businesses. This void takes place because financial advisors rarely take the time to work with small businesses because they believe it is difficult for them to make money in this environment. Therefore, small business owners are left to fend for themselves and are usually uninformed or misinformed about what their workplace retirement plan options are and the costs associated with those options. Most small business owners believe the $401(\mathrm{k})$ plan is the only option available, and that is too expensive and requires too many internal resources to operate.

I combine two artefacts, the elicitation script and the adaptive default nudge in the Design Cycle to educate the small business owner and then guide their decision-making process. The elicitation script is a series of eight general questions designed to have the small business owner talk about some of their challenges to growth and the importance of attracting and retaining quality employees. I follow this with a brief education of three plan types, the 401(k), the SIMPLE IRA, and the Payroll Deduction IRA. I finish the elicitation script with seven polling questions designed to determine the best plan type for that individual based on their particular situation. This script is followed by an adaptive default nudge, which presents four options: the three plan types, and the fourth option, which is no plan. One of the options is pre-selected as a "best fit" option based on the information I gather. One option is no plan, because freedom of choice is a key tenet of nudging

\section{Worker and Retiree Savings Amounts, by Plan vs. No Plan}

\section{In total, about how much money would you say you (and your spouse) currently have in savings and investments, not including the value of your primary residence or defined benefit plan assets?}

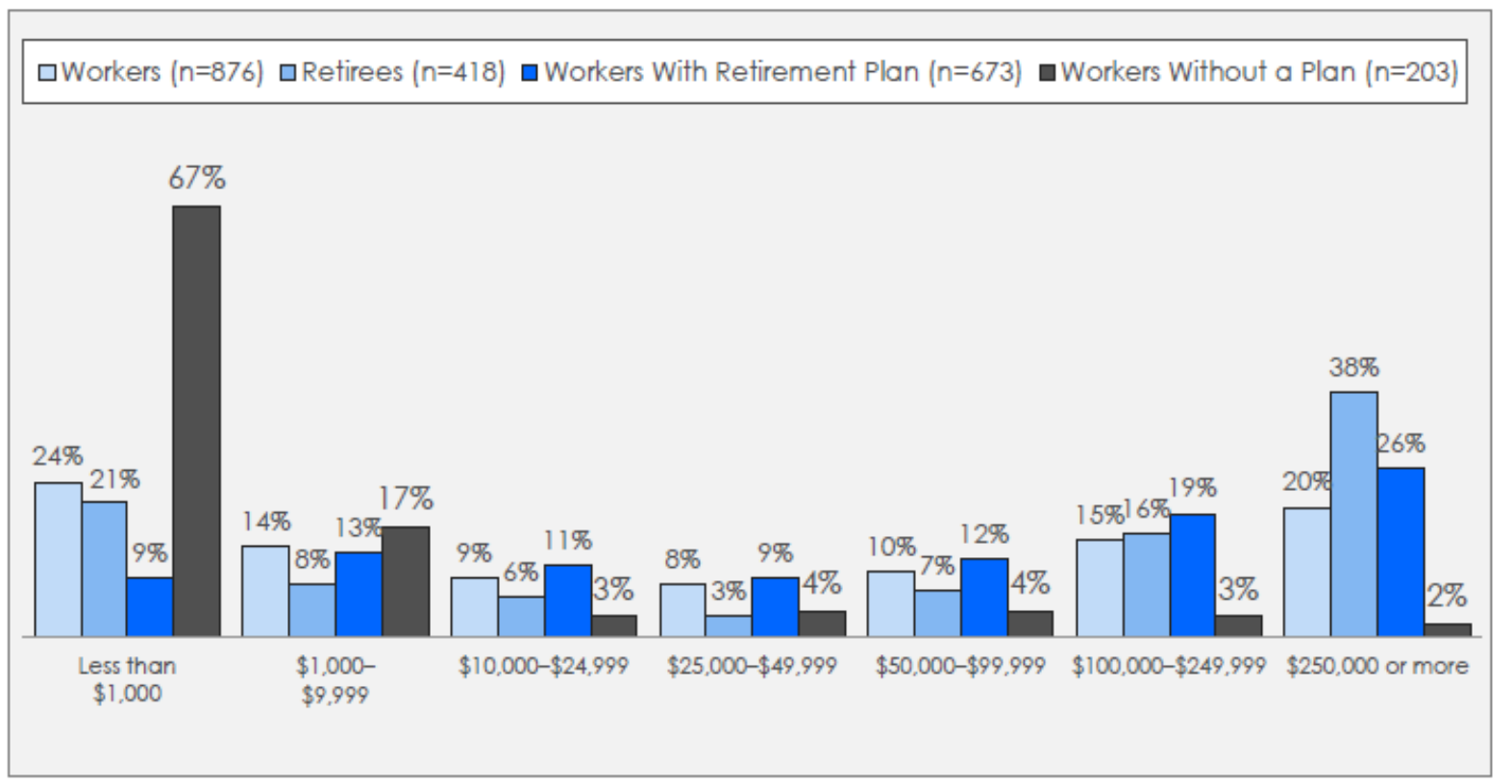

Source: Employee Benefit Research Institute and Greenwald \& Associates, 2017 Retirement Confidence Survey.

Figures and $n$-sizes presented exclude those who answered "Don't know," said they never worked, or refused to answer.

Figure 1: Worker Savings Amounts (Reprinted by Permission) 
principles. In most cases, the small business owner agreed with the pre-selected option. Many stated that they felt counseled and consulted, and the process gave them confidence in their selection.

The practical implications of these findings is the education of financial advisors on how they can sell to small business owners and support them in a profitable manner. Another practical implication is the opportunity to create a web-based portal that can deliver the same experience to tens of thousands of small business owners and increase workplace retirement plan adoption in a meaningful fashion.

Limitations on the research include sample size and geographic dispersity of the group of small businesses interviewed.

\section{Conclusions}

The results of the research tell us that small business owners have identified employees as their biggest obstacle to growth. Specifically, attracting and retaining quality employees. This research goes on to tell us that small business owners are uniformed and/or misinformed about their options related to workplace retirement plans, and when briefly educated, they are significantly more likely to adopt a workplace retirement plan.

\section{Where to Find Out More}

More information about this research can be found in Closing America's Retirement Savings Gap: Nudging Small Business Owners to Adopt Workplace Retirement Plans (Kirtland, 2019).
Center for Retirement Innovation 2018 Policy Innovation Forum Report, June 2018. Retrieved from https://cri.georgetown.edu/wp-content/ uploads/2019/02/CRI-Policy-Forum-Report-2-28-19.pdf

U.S. Government Accountability Office, The nation's retirement system: A comprehensive re-evaluation is needed to better promote future retirement security. GAO-18-111SP: October 18, 2017. Retrieved from https://www.gao.gov/products/ gao-18-111sp

Kirtland, P. W. (2019.) Closing America's retirement savings gap: Nudging small business owners to adopt workplace retirement plans. Doctoral Dissertation. Retrieved from https:// scholarcommons.usf.edu/cgi/viewcontent. cgi? article $=9239 \&$ context $=$ etd

\section{Review}

This article was accepted under the constructive peer review option. For futher details, see the descriptions at:

http://mumabusinessreview.org/peer-review-options/

\section{Author}

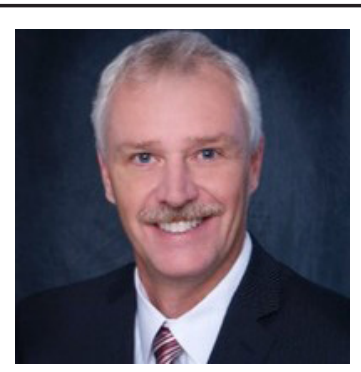

Peter W. Kirtland is the CEO of Aspire Financial Services, a company delivering technology and administration services to over 250,000 retirement plan participants. He was the Florida finalist for Ernst \& Young's prestigious Entrepreneur of the Year award in 2010, his company was named one of the 50 fastest growing companies in the Tampa Bay Business Journal in 2011 and 2015, and he was a semi-finalist for the Tampa Chamber of Commerce's Small Business Award in 2013 and 2014. His bachelor's degree in finance is from Pennsylvania State University. He received his Doctor of Business Administration from the University of South Florida's Muma College of Business. 